\title{
Numerical simulation of magma intrusion on the thermal evolution of low rank coal
}

Jingyu Jiang ( $\sim$ jiangjingyu@cumt.edu.cn )

China University of Mining and Technology https://orcid.org/0000-0001-9853-7487

\section{Ke Zhao}

China University of Mining and Technology

\section{Yuanping Cheng}

China University of Mining and Technology

\section{Shaojie Zheng}

China University of Mining and Technology

\section{Shuo Zhang}

China University of Mining and Technology

\section{Ran Wang}

China University of Mining and Technology

\section{Research Article}

Keywords: Magmatic sill, Low rank coal, Moisture, Thermal effect, Thermal conductivity

Posted Date: February 12th, 2021

DOl: https://doi.org/10.21203/rs.3.rs-218417/v1

License: (c) (i) This work is licensed under a Creative Commons Attribution 4.0 International License. Read Full License

Version of Record: A version of this preprint was published at Environmental Earth Sciences on August 16th, 2021. See the published version at https://doi.org/10.1007/s12665-021-09871-5. 


\section{Numerical simulation of magma intrusion on the thermal evolution of low rank coal}

Jingyu Jiang a, b, c*, Ke Zhao a, b, Yuanping Cheng a, b, Shaojie Zheng a, b, Shuo Zhang a, b, Ran Wang a,b

a Key Laboratory of Gas and Fire Control for Coal Mines (China University of Mining and Technology),

Ministry of Education, Xuzhou, 221116, China

b School of Safety Engineering, China University of Mining and Technology, Xuzhou, Jiangsu 221116,

China

c Artificial Intelligence Research Institute, China University of Mining and Technology, Xuzhou, Jiangsu 221116, China

* Correspondence to: Jingyu Jiang

Email: jiangjingyu@cumt.edu.cn

Tel: +86-516-83885948

Fax: +86-516-83995097 
Abstract: To study the effect of magma intrusion on the thermal evolution of low-rank coal with high water content, the mathematical relationship between water content variation and thermal conductivity of low-rank coal was analyzed by COMSOL Multiphysics numerical simulation and field validation. Taking Daxing Mine in Tiefa coalfield as the research background, the effects of magma finite time intrusion mechanism and water volatilization in coal on thermal evolution and organic maturity of coal seam are investigated in this paper. The results show that as the sill thickness increases, the thermal evolution temperature of the coal seam increases, the required thermal evolution time increases and the final retention temperature increases after the coal seam is cooled down. Approaching the magma, the maximum temperature that the coal seam can reach increases, the maximum temperature lasts longer, and the final temperature retained by the coal seam becomes higher. The increase of water content of coal makes the thermal conductivity increase, and the rate of heat transfer from coal seam is accelerated, and more heat is transferred to distant places in the same time. At the same time, the heat lost by the magma in the same time increases, the time required for the cooling of the magma decreases, and the maximum temperature reached by the underlying coal seam is significantly lower. The presence of moisture weakens the thermal evolution of the magma to the coal seam and reduces the expected maturity of the coal. The results of average random vitrinite reflectance $\left(R_{o}\right)$ and moisture examination of coal samples collected at the Daxing Mine site verified the numerical simulation results of magma thermal evolution.

Keywords: Magmatic sill; Low rank coal; Moisture; Thermal effect; Thermal conductivity 


\section{Introduction}

Magmatic intrusion into coal-bearing strata occurs in many regions worldwide, such as the Colorado (Dutcher et al. 1968; Finkelman et al. 1998) in the United States, the Huaibei Mining District (Wang et al. 2014) in China, the Kyushu region (Sasaki 1959) in Japan, the west coast of Australia (Charles et al. 1998), and the Karoo Basin (Aarnes et al. 2011) in South Africa. Statistics of coal and gas protrusion accident cases show that the magma intrusion zone is a high incidence area for protrusion accidents (Beamish and Crosdale 1998; Golab and Carr 2004; Sachsenhofer et al. 2012). Several researchers have used petrographic and geochemical methods to study the effect of magma intrusion on the organic maturity of coal (Sachsenhofer et al. 2012; Rahman and Rimmer 2014). The maturation process of the coal is accelerated under the high temperature and pressure environmental conditions following magma intrusion (Wang et al. 2010a). Magma intrusion changes the physicochemical properties of the coal, including molecular structure of coal (Jiang et al. 2017), degree of metamorphism (Shivanna et al. 2015; Saikia et al. 2016; Fjeldskaar et al. 2008), pore structure, and adsorption/desorption properties. Magma intrusion can cause changes or abrupt changes in the coal seam gas assignment pattern and gas prominence indicators (Jiang et al. 2011; Jiang et al. 2019).

Several researchers have used numerical simulations to study the thermal effects of magmatic intrusion on coal (Wang 2013a; Charles et al. 1998; Wang et al. 2010b). Heat flow models are widely used to study the thermal evolution of magma intrusion into surrounding rocks or nearby coal seams. Wang et al. (2013a) numerically simulated the heat transfer process of magma intrusion into coal seams to their surrounding rocks using the MagmaHeatNS1D interactive data language program (based on a complete one-dimensional heat flow models), which can respond many recent theoretical studies on one-dimensional heat transfer models of magma intrusion. Charles et al. (1998) compared results from contact metamorphic heat flow models and fluid inclusions with average random vitrinite reflectance $\left(R_{\circ}\right)$ back-calculated paleotherm results and showed that heat flow models based on simple conduction cooling in closed geological systems do not accurately calculate the temperatures reached during contact metamorphism. A heat conduction model was established to describe the heat dissipation of magmatic intrusions, and further combined with the Easy $\mathrm{R}_{\mathrm{o}} \%$ model 
to perform a model test on the reflectivity $R_{o}$ data of the specular mass, showing that the simulation results fit well with the measured results, and the model can better describe the organic matter maturity evolution of the surrounding rocks of magmatic intrusions (Wang et al. 2010b). Wang et al. (2012) tested the heat flow model by comparing experimental data of vitrinite reflectance and mineral geothermometer of the surrounding rocks with the simulation results, which fit well and showed that magma intrusion can significantly accelerate the rate of hydrocarbon generation in the surrounding rocks. There are also models that consider the role and importance of the latent heat of magma crystallization (Jaeger 1957; Carslaw and Jaeger 1959), the intrinsic heat of the intrusive body (Galushkin et al. 1997), the mechanism of magma intrusion (Yang et al. 1996), and the mode of heat flow (Jaeger 1959) on the thermal evolution of coal rocks.

Low rank coal is characterized by high natural water content, and the volatilization of pore water during the cooling of the magma intrusion when the coal seam contains water will significantly change the thermal evolution of the intruded coal seam (Jaeger 1959; Wang et al. 2007). The study of numerical simulation of magma thermal evolution showed that the volatilization of pore water would significantly reduce the predicted organic maturity of the surrounding rock (Wang et al. 2011). In the study of numerically simulated magmatic thermal effects, saturated water treatment of coal was considered to compare the changes of thermal conductivity and diffusion coefficient of coal before and after treatment, and the results showed that the thermal conductivity and diffusion coefficient of rocks increase with decreasing temperature, and these properties become more obvious after saturated water treatment of rocks at low temperatures (Delaney 1988). However, in the literature on numerical simulation of magmatic thermal evolution of coal, there are few papers that consider the relationship between moisture and thermal conductivity of coal, and there are few studies on the issue that changes in moisture of coal seams affect the effect of magmatic thermal evolution of coal.

The low rank coal of Daxing Mine in Tiefa, China, is severely intruded by magma, and ten coal and gas outbursts have occurred in Daxing Mine since the construction of the mine, all of which occurred in coal seams near the igneous erosion zone, and 9 of them have occurred in the No.7 coal seam, which is severely intruded by magma. In this paper, we will simulate the 
effects of different sill thickness, distance between magma and coal seam, and different moisture on the thermal evolution of coal seam with the help of COMSOL numerical simulation software, analyze the mathematical relationship between moisture and thermal conductivity of coal seam, and study the effect of moisture on the magma thermal evolution of coal. And the moisture and $R_{o}$ were measured by sampling in the coal seam in the magma intrusion area of Daxing Mine to carry out the validation study.

\section{Methods}

\subsection{Basic theory of heat flow}

Heat conduction, heat convection and heat radiation are the three forms of heat flow (Yang et al. 2006). The way of heat flow by heat conduction only depends on the thermal motion of micro particles. The heat conduction of porous media includes three processes: the heat conduction process of solid particles; the heat conduction process between fluids in pores and between solid particles and fluids; and the heat conduction process when there is contact thermal resistance between solid particles (Yang et al. 2006). As a kind of porous medium, coal is more complex than single solid in the heat flow process. The process of heat flow is more complex and accompanied by material migration.

Magmatic intrusion is an unsteady process, which causes the strata to reach a high temperature in a short time. After magma intrusion, it mainly transfers heat to surrounding coal by means of heat conduction. Although heat convection and heat radiation also exist, it is much weaker than heat conduction. The study of heat conduction is mainly about the spatial distribution of temperature over time, expressed by T, which is expressed as Eq. (1) (Wang et al. 2014):

$$
T(x, y, z)=f(x, y, z, t)
$$

Where $\mathrm{x}, \mathrm{y}, \mathrm{z}$ are three-dimensional coordinates and $\mathrm{t}$ is time. The intrusion process of magma is an unsteady heat conduction process, $t \neq 0$. Fourier law reveals the relationship between the heat flux density and the temperature gradient in a heat conducting object, and the mathematical expression is Eq. (2):

$$
Q=-\lambda F \frac{\partial T}{\partial n}
$$


Where $\mathrm{q}$ is the heat, $\mathrm{J} ; \lambda$ is the thermal conductivity, $\mathrm{W} \cdot(\mathrm{m} \cdot \mathrm{K})^{-1} ; \mathrm{F}$ is the heat area, $\mathrm{m}^{2}$; a negative sign indicates that the heat is transferred towards the direction of low temperature. The thermal evolution of magma on the surrounding rock or coal can improve the organic maturity of the surrounding rock (Rahman et al. 2014; Wang et al. 2010a). The $R_{o}$ of coal is usually used to represent its organic maturity. The paleotemperature $T_{\text {peak }}$ (Barker et al. 1994) of thermal evolution of magma can be inverted by coal rock $R_{o}$, which is expressed as Eq. (3):

$$
T_{\text {peak }}=\left[\ln \left(R_{0}\right)+1.19\right] / 0.00782
$$

\subsection{Magmatic rock heat flow model considering the influence of coal water}

Magma intrusion is a long-term and complicated process, and the heat flow of porous media is also very complicated. The change of coal seam temperature is affected by many factors. In order to facilitate research, the process needs to be simplified and assumed. It is assumed that the skeleton of coal is stable and not deformed during magma intrusion; there is no internal heat source in coal and no heat is generated; magma intrusion mechanism is instantaneous intrusion mechanism; the heat flow mode is heat conduction, and the influence of convection and heat radiation on magmatic intrusion process is ignored. The coal seam has uniform moisture, and the water content is the same everywhere in the coal seam.

According to the above assumption, the mathematical heat flow model of magmatic thermal evolution coal is established under the condition of considering different water content in coal. The energy change $\mathrm{Q}_{\text {produce }}$ in the micro-element body within $\mathrm{dt}$ time is the mass of the micro-element body multiplied by the heat capacity $\mathrm{C}$ multiplied by the temperature change of the micro-element body in time $\mathrm{dt}$, and the calculation refers to Eq. (4) (Wang et al. 2014):

$$
Q_{\text {produce }}=\rho d x d y d z c \frac{\partial T}{\partial_{t}}=\left(\rho c \frac{\partial T}{\partial_{t}}\right) d x d y d z
$$

After intrusion, the magma condenses and crystallizes with water, resulting in phase transformation (Wang et al. 2010b; Wang et al. 2011). The heat consumption of magma micro element phase transformation is $\mathrm{H}_{1}$, and its mathematical expression is Eq. (5):

$$
H_{1}=\rho_{1} \cdot \frac{L_{c}}{T_{c 1}-T_{c 2}} \cdot \frac{\partial T}{\partial t}
$$


Where $\rho_{1}$ is the density of magma, $\mathrm{kg} / \mathrm{m}^{3} ; \mathrm{L}_{\mathrm{c}}$ is the latent heat of magma transformation, $\mathrm{kJ} / \mathrm{kg} ; \mathrm{Tc}_{1}-\mathrm{Tc}_{2}$ is the temperature range of magma transformation, that is, magma transformation occurs in this temperature range. According to the law of conservation of energy, the heat input per unit time is equal to the sum of the heat output per unit time, the change of the internal energy of the derived magma, and the internal energy consumed by the phase transformation of the magma, which is expressed as Eq. (6) (Wang et al. 2014):

$$
\frac{\partial}{\partial x}\left(\lambda_{x} \frac{\partial T}{\partial \mathrm{x}}\right)+\frac{\partial}{\partial y}\left(\lambda_{y} \frac{\partial T}{\partial \mathrm{y}}\right)+\frac{\partial}{\partial z}\left(\lambda_{z} \frac{\partial T}{\partial \mathrm{z}}\right)=\rho_{1} c_{1} \frac{\partial T}{\partial \tau}+H_{1}
$$

In engineering problems, it is often considered that the thermal conductivity of an object is the same everywhere under the same condition. The formula can be simplified as Eq. (7):

$$
\lambda_{1}\left(\frac{\partial^{2} T}{\partial \mathrm{x}^{2}}+\frac{\partial^{2} T}{\partial \mathrm{y}^{2}}+\frac{\partial^{2} T}{\partial \mathrm{z}^{2}}\right)=\rho_{1} c_{1} \frac{\partial T}{\partial \tau}+H_{1}
$$

Where $\lambda_{1}$ is the thermal conductivity of magma, $\mathrm{W} \cdot(\mathrm{m} \cdot \mathrm{K})^{-1} ; \mathrm{c}_{1}$ is the specific heat capacity of magma, $\mathrm{J} \cdot(\mathrm{kg} \cdot \mathrm{K})^{-1}$. The coal seam is baked by magma, and the temperature rises continuously. After reaching a certain temperature, the water in the coal seam will change phase. At this time, the coal seam continues to absorb heat, but the temperature is no longer rising, and the absorbed heat is used for water phase transformation (Wang et al. 2011; Wang et al. 2013b). The heat record of phase change absorption of water in coal micro element object is $\mathrm{H}_{2}$, and its mathematical expression is Eq. (8):

$$
H_{2}=\rho_{w} \cdot \frac{L_{v} \cdot w}{T_{v 1}-T_{v 2}} \cdot \frac{\partial T}{\partial t}
$$

Where $\rho_{\mathrm{w}}$ is the density of water, $\mathrm{kg} / \mathrm{m} ; \mathrm{L}_{\mathrm{v}}$ is the latent heat of phase change of water, $\mathrm{kJ} / \mathrm{kg}$; $\mathrm{w}$ is the water content, dimensionless; $\mathrm{T}_{\mathrm{v} 1}-\mathrm{T}_{\mathrm{v} 2}$ is the temperature range of phase change, that is, the phase change of water occurs in this temperature range.

Based on the law of conservation of energy, the heat introduced into the coal micro element in unit time is equal to the sum of the heat derived from the coal micro element in unit time, the change of the internal energy of the coal micro element and the internal energy absorbed by the water contained in the coal micro element in phase change, which is expressed as Eq. (9): 


$$
\frac{\partial}{\partial x}\left(\lambda_{x} \frac{\partial T}{\partial \mathrm{x}}\right)+\frac{\partial}{\partial y}\left(\lambda_{y} \frac{\partial T}{\partial \mathrm{y}}\right)+\frac{\partial}{\partial z}\left(\lambda_{z} \frac{\partial T}{\partial \mathrm{z}}\right)=\rho_{2} c_{2} \frac{\partial T}{\partial \tau}+H_{2}
$$

Assuming that the thermal conductivity of the coal seam is the same, the simplified differential equation of heat conduction is shown in Eq. (10):

$$
\lambda_{2}\left(\frac{\partial^{2} T}{\partial \mathrm{x}^{2}}+\frac{\partial^{2} T}{\partial \mathrm{y}^{2}}+\frac{\partial^{2} T}{\partial \mathrm{z}^{2}}\right)=\rho_{2} c_{2} \frac{\partial T}{\partial \tau}+H_{2}
$$

Where $\lambda_{2}$ is the thermal conductivity of coal, $\mathrm{W} \cdot(\mathrm{m} \cdot \mathrm{K})^{-1} ; \rho_{2}$ is the density of coal, $\mathrm{kg} / \mathrm{m}^{3} ; \mathrm{c}_{2}$ is the specific heat capacity of coal, $\mathrm{J} \cdot(\mathrm{kg} \cdot \mathrm{K})^{-1}$.

\subsection{Relationship between moisture and thermal conductivity of low rank coal}

Phase change materials are involved in the mathematical model of heat flow considering the influence of water, and the physical and chemical properties will change before and after phase change, which has a great influence on the simulation results. In the process of simulating temperature change, the thermal conductivity of material is very important, and the relationship between moisture of coal and thermal conductivity needs to be studied.

Ma et al. (2017) investigated the relationship between the thermal conductivity and moisture of coal samples at different temperatures for non-stick coal, and the results are shown in Fig. 1(Ma et al. 2017).

Fig. 1 indicates that when the moisture of non-caking coal is $0-13.90 \%$, the thermal conductivity of coal increases rapidly; when the moisture is $13.90 \%-15.13 \%$, the thermal conductivity increases greatly; when the moisture is $15.13 \%-20.0 \%$, the thermal conductivity of coal has a small increase (Ma et al. 2017). It shows that with the increase of moisture, the thermal conductivity of coal has an increasing trend; but when the moisture of coal reaches a certain critical value, it has little effect on the thermal conductivity of coal.

$\mathrm{Xu}$ and Zhan (2010) show that the effective thermal conductivity of unsaturated porous media is significantly affected by water content. Based on three theoretical models (parallel conduction model, series model and Woodside-Messmer model), the relationship between effective thermal conductivity and water content is calculated and verified by experiments. The results show that the experimental results are in good agreement with the theoretical values of WM model (Pan 2000). According to WM model, the relationship between moisture content and thermal conductivity is expressed as Eq. (11) (Pan 2000): 


$$
\lambda_{e}=\alpha \lambda_{0}\left(g \frac{\lambda w}{\lambda_{g}}\right)^{\frac{w}{\rho} \frac{\rho_{2}}{\rho \omega}}
$$

Where $\lambda_{\mathrm{e}}$ is the effective thermal conductivity, $\mathrm{W} \cdot(\mathrm{m} \cdot \mathrm{K})^{-1}$; $\mathrm{a}$ is the correction coefficient, dimensionless, different values for different materials, this paper takes 0.8 ; $\lambda_{0}$ is the thermal conductivity of skeleton, $\mathrm{W} \cdot(\mathrm{m} \cdot \mathrm{K})^{-1} ; \lambda_{\mathrm{W}}$ is the thermal conductivity of water, $\mathrm{W} \cdot(\mathrm{m} \cdot \mathrm{K})^{-1} ; \lambda_{\mathrm{g}}$ is the thermal conductivity of air, $\mathrm{W} \cdot(\mathrm{m} \cdot \mathrm{K})^{-1}$.

\subsection{Numerical simulation}

In order to study the temperature change law of low rank coal with high water content after magma intrusion, COMSOL Multiphysics numerical simulation software was used to study the temperature distribution law of heat conduction between sill and Water-bearing coal seams, and the influence of different water content of coal seam on the temperature change of coal seam after magmatic intrusion.

Before the numerical simulation, the relevant parameters are assigned, and the parameter content and assignment basis are shown in Table 1 (Wang et al. 2011; Xu et al. 2010; Hu et al. 2016; Thussu and Datta 2011; Shang et al. 2012).

Since the influence of moisture is considered in the simulation, the physical property parameters before and after the phase change of the material need to be set. The setting content and basis are shown in Table 2 (Wang et al. 2017).

In this simulation, four kinds of water content are selected as $50 \%, 30 \%, 8 \%$, and $3 \%$ respectively. According to Eq. (11), the thermal conductivity of coal can be calculated. The results are shown in Table 3.

According to the site and the need of model simplification, the upper boundary of the model is set as an open boundary, and the left and right boundaries and the lower boundary are set as thermal insulation. The transient equation of boundary application is shown in Eqs. (12-15):

$$
\begin{aligned}
& -n \cdot(-k \nabla T)=0 \\
& T=T_{0}, \quad \text { ifn } \cdot u<0 \\
& -\nabla T n=0, \quad \text { if } n \cdot u \geq 0
\end{aligned}
$$


The open boundary defaults to $\mathrm{T}=\mathrm{T}_{0}=30^{\circ} \mathrm{C}$. The selected physical field is heat flow in solids, and the solution to the transient equation is:

$$
\rho C_{p} \frac{\partial T}{\partial t}+\rho C_{p} u \cdot \nabla T=\nabla(k \nabla T)+Q
$$

\section{Results and discussion}

\subsection{Analysis of the influence of sill thickness on the thermal evolution of coal seams}

Based on the multi-physics coupling software COMSOL with finite element solution, a numerical simulation of the heat conduction temperature distribution between magma and surrounding rock was established. Before the simulation, the relative positions of the simulated sill, coal, and surrounding rock need to be simplified and the boundary should be set, and then the three are modeled in COMSOL. Since the thermal conductivity of the three main bodies is different and the initial temperature is different, the whole model needs to be divided into three in the modeling. The model set up the minefield is $2000 \mathrm{~m}$ long and $1000 \mathrm{~m}$ wide; the sill is $1000 \mathrm{~m}$ long and its thickness can be adjusted. According to No. 7 coal seam of Daxing Mine, the coal seam is located $10 \mathrm{~m}$ below the sill, and the set coal seam is $1800 \mathrm{~m}$ long, 3.5m thick, and 10m away from the magma floor. A model is established as shown in Fig. 2.

Set surface temperature $T_{1}$ to $20^{\circ} \mathrm{C}$, surrounding rock temperature $T_{2}$ to $30^{\circ} \mathrm{C}$, initial magma temperature $\mathrm{T}_{3}$ to $1000^{\circ} \mathrm{C}$, other parameter settings are shown in Table 1, magma thickness is set to $50 \mathrm{~m}, 80 \mathrm{~m}, 10 \mathrm{~m}$, simulation time is set to $1000 \mathrm{a}$. The simulation results are shown in Fig. 3. Fig. 3 indicates that the temperature of the coal seam rises sharply after magma intrusion, reaching the highest temperature in the first 100 years, and then the temperature begins to decrease slowly. The greater the thickness of the magma, the higher the maximum temperature reached by the coal seam. When the thickness of magma is $50 \mathrm{~m}$, the maximum coal seam temperature is $380^{\circ} \mathrm{C}$; when the thickness of magma is $80 \mathrm{~m}$, the maximum coal seam temperature reaches $420^{\circ} \mathrm{C}$; when the thickness of magma is $100 \mathrm{~m}$, the maximum coal seam temperature is close to $450^{\circ} \mathrm{C}$. As the thickness of magma increases, the maximum coal seam temperature lasts longer. When the thickness of magma is $50 \mathrm{~m}, 80 \mathrm{~m}$ and $100 \mathrm{~m}$, the time for the coal seam to reach the maximum temperature is $30 \mathrm{a}, 50 \mathrm{a}$ and $70 \mathrm{a}$ respectively. This is roughly consistent with the temperature variation trend in the simulation results of Wang et al. (2014). However, the distance between the sill and the coal field roof is 
far greater than the simulated distance set in this study, so the temperature variation is lower than the temperature variation results in this study.

\subsection{Influence of the distance from magma on the thermal evolution of coal}

Model 2 sets up a minefield of $2000 \mathrm{~m}$ long and $1000 \mathrm{~m}$ wide; the magmatic rock mass is $1000 \mathrm{~m}$ long and $50 \mathrm{~m}$ thick; the coal seam is $1800 \mathrm{~m}$ long and $2 \mathrm{~m}$ thick. The distances from the floor of the sill are 10m, 20m, 30m, 40m, and 50m, respectively. Model 2 is shown in Fig. 4.

Set the surface temperature $\mathrm{T}_{1}$ to $20^{\circ} \mathrm{C}$, the surrounding rock temperature $\mathrm{T}_{2}$ to $30^{\circ} \mathrm{C}$, the initial magma temperature $\mathrm{T}_{3}$ to $1000^{\circ} \mathrm{C}$, the other parameters are shown in Table 1 , and the simulation time is set to 1000a. The simulation results are shown in Fig. 5.

Fig. 5 (a) shows the coal seam temperature rose sharply after magma intrusion, reaching the highest temperature in the first 100a, and then decreasing slowly. Closer the coal seam is to the magma, higher the maximum temperature of the coal seam is, and the required time is 20a, 40a, 60a, 90a, 120a respectively. After the magma cools, the closer the magma is, the higher the final temperature of the coal seam, but the difference is smaller. Fig. 5(b) shows that the closer the distance to the magmatic rock, the $R_{o}$ of coal and the peak temperature of magma thermal evolution have an increasing trend. It shows that the thermal evolution of magma significantly improves the organic maturity of coal. From $50 \mathrm{~m}$ to $10 \mathrm{~m}$ away from the magma, the $\mathrm{R}_{\mathrm{o}}$ of coal increases by $11.32 \%$ from $1.25 \%$, and the peak temperature of magma increases from $180.18{ }^{\circ} \mathrm{C}$ to $462.50{ }^{\circ} \mathrm{C}$.

\subsection{Effect of water content on coal seam heat conduction during magma cooling}

In order to study the influence of different water cuts during the cooling process of magma intrusions on the thermal evolution of coal seams, the model is further simplified, assuming that the thermal conductivity of surrounding rock and coal sea. Model 3 set up the mine field $1000 \mathrm{~m}$ long and $500 \mathrm{~m}$ wide; the magmatic rock mass is $400 \mathrm{~m}$ long, $50 \mathrm{~m}$ wide and 225m above the ground. Model 3 is shown in Fig. 6.

Set the surface temperature $\mathrm{T}_{1}$ to $20^{\circ} \mathrm{C}$, the surrounding rock temperature $\mathrm{T}_{2}$ to $30^{\circ} \mathrm{C}$, the initial magma temperature $\mathrm{T}_{3}$ to $1000^{\circ} \mathrm{C}$, the other parameters are shown in Table 1 , and the simulation time is set to 1000a. The simulation result is shown in Fig.7.

The heat lost by the magma in the same time is used for its own phase change and heat flow in coal, which increases with the decrease of the central temperature of the magma. 
Therefore, with the increase of coal seam moisture content, the heat loss of magma increases in the same time. Fig. 7(a) indicates that after 100a, the coal seam moisture content increases from $0 \%$ to $50 \%$, and the maximum temperature reached by the coal seam decreases from $540{ }^{\circ} \mathrm{C}$ to $280^{\circ} \mathrm{C}$.Under high temperature conditions, coal will go through two stages of drying degassing and coal matrix pyrolysis (Su et al. 2020), and part of the heat of magma intrusion was absorbed in the degassing process of water in coal, so the higher the moisture of coal seam, the lower the temperature after magma intrusion.

Comparing magma intrusion at 100a, 500a and 1000a, the water content is the same, and the temperature of the coal seam at the same depth is lowered. Comparing Figs. 7(a), 7(b), and $7(\mathrm{c})$, it can be seen that as the simulation time increases, the coal temperature has a decreasing trend. The greater the water content of coal, the smaller the increase in temperature near the magmatic coal. This is because the increase of the water content of coal leads to the greater the thermal conductivity of its own, the more heat transferred to the distance. In addition, more heat is consumed for the phase transition of water, the lower the coal temperature is.

The time required for magma cooling decreases with the increase of water content. Fig. 7(c) indicates that at $1000 \mathrm{a}$, when the water content is $0 \%, 3 \%$, and $8 \%$, the temperature of the magma center is higher and the temperature changes at different depths. When the water content is $30 \%$ and $50 \%$, the temperature change is small, and the magma cools quickly. It is studied that after 8000 years of magma intrusion in coal mines, magma and surrounding rocks reach a geothermal balance, but the deep geothermal of coal mines is abnormal, and its stratigraphic characteristics, geological structure and groundwater flow activities are the main factors leading to its abnormality (Feng et al. 2020). After the magma was cooled, the greater the water content, the lower the temperature retained by the coal seam. After 1000a of magma intrusion, the water content increased from $0 \%$ to $50 \%$, and the coal seam retention temperature decreased from $95^{\circ} \mathrm{C}$ to about $87^{\circ} \mathrm{C}$.

\subsection{Temperature variation with time for coals with different water content}

Wang Dayong et al. created a magma intrusion model, compared the numerical simulation with the measured results, and studied the effect of pore water volatilization and supercritical state on the degree of coal metamorphism. The results show that when a limited 
time intrusion mechanism is used, the effect of pore water on the degree of metamorphism is predicted. The deviation is slightly lower, which indicates that the limited time intrusion mechanism of magma and the volatilization of pore water may represent natural conditions (Wang et al. 2011). In order to study the influence of water content on coal seam temperature and degree of metamorphism, combined with the actual situation of the Daxing Mine field, Model 4 sets the mine field $2000 \mathrm{~m}$ long and $1000 \mathrm{~m}$ wide; the magmatic rock mass is $1000 \mathrm{~m}$ long and $50 \mathrm{~m}$ wide. The coal seam is $1800 \mathrm{~m}$ long, $4 \mathrm{~m}$ wide, and $50 \mathrm{~m}$ away from the magma floor. Model 4 is shown in Fig. 8.

Set the surface temperature $\mathrm{T}_{1}$ to $-10^{\circ} \mathrm{C}$, the surrounding rock temperature $\mathrm{T}_{2}$ to $30^{\circ} \mathrm{C}$, the initial magma temperature $\mathrm{T}_{3}$ to $500^{\circ} \mathrm{C}$, the other parameters are shown in Table 1 , and the simulation time is set to 5000a. The simulation result is shown in Fig. 9. Fig. 9(a) shows that as the moisture content increases, the maximum temperature reached by the coal seam decreases significantly, and the time to reach the maximum temperature becomes shorter. When the moisture content increases from $0 \%$ to $50 \%$, the maximum coal seam temperature drops from about $120^{\circ} \mathrm{C}$ to $35^{\circ} \mathrm{C}$ (Fig.9a). The coal $R_{o}$ is reduced from $0.78 \%$ to $0.40 \%$ (Fig. $9 b$ ). The comparative analysis of Figs. 5 and 9 shows that the presence of moisture reduces the maximum temperature that the coal seam can reach, weakens the thermal evolution of magma on the coal seam, and thereby weakens the degree of coal seam metamorphism.

\subsection{Verification of moisture and $R_{0}$ of coal seam in in-situ magmatic intrusion area}

Daxing Mine is located in Tiefa coalfield, Tieling City, Liaoning Province. magmatic movement in Tiefa coalfield can be divided into three stages in time. The early stage of late Jurassic is the first stage. The main movement form of magma is eruption, and the coalfield began to deposit in this stage. The second stage is the middle and late stage of Early Cretaceous, with the end of stratigraphic deposition, followed by more frequent magmatic activity, and eruption is still the main form of magmatic activity. The Tertiary period is the last stage, the magmatic activity is no longer dominated by eruption, replaced by the intrusion of basic magmatic rocks, with multiple intrusions into the roof and floor of coal seam and a few intrusions into rock strata.

The magmatic rock exposed in Daxing Mine field is the third stage of basic magmatic rock intrusion. There is a stable distribution of sill in the roof of $\mathrm{N}_{1} 708$ working face of No.7 coal 
seam, with an average thickness of $3.5 \mathrm{~m}$. The magma intruded along the roof of No.7 coal seam with a vertical distance of about $10 \mathrm{~m}$. The distribution plan of $\mathrm{N}_{1} 708$ working surface and sill in Daxing Mine is shown in Fig. 10 (Jiang et al. 2016).

In the previous study, 15 coal samples were taken from No.7 coal seam in the range of 0 to 250m from the sill, and the industrial analysis and vitrinite reflectance measurement were carried out in the laboratory. Based on the determination results of moisture and $\mathrm{R}_{\mathrm{o}}$ (Jiang et al. 2016), the relationship between moisture content, $R_{o}$ and the distance between coal sample and sill is plotted, as shown in Fig. 11.

Fig. 11 indicates that the intrusion of sill reduces the moisture content of coal and improves the metamorphic degree of coal. Near the sill, the water content of coal decreases from $7.5 \%$ to $1.6 \%$, and $R_{o}$ increases from $0.53 \%$ to $1.58 \%$ (Fig. $11 \mathrm{a}$ ). The peak temperature of magmatic thermal evolution increases from $82.52^{\circ} \mathrm{C}$ to $210.67^{\circ} \mathrm{C}$ when the distance changes from $264 \mathrm{~m}$ to $0.1 \mathrm{~m}$ (Fig.11b). The above research results to some extent verify the numerical simulation results of magma thermal evolution coal. The thermal evolution of magma increases the degree of metamorphism of low-rank coals. Magma baking or heat conduction reduces the vaporization and evaporation of water in coal. In addition, due to high water content $(7.5 \%)$ of low rank coal in Daxing Mine, the thermal effect of magma intrusion on coal reduced to a certain extent, thereby reducing the degree of coal metamorphism.

\section{Conclusions}

In this paper, the relationship between moisture content and thermal conductivity of coal is investigated by using numerical simulation and field verification method. The relationship between sill thickness, distance from igneous sill, organic maturity of coal and time of magma thermal evolution are analyzed by numerical simulation. Further, the temperature of the cooled coal is analyzed in relation to the moisture content, and the main conclusions are as follows:

1) The establishment of magma thermal evolution coal and heat flow model shows that the main factors affecting the change of coal seam temperature are: initial magma temperature, thickness of magma, thermal conductivity of coal and the distance between coal and magma. There is an inherent relationship between the thermal conductivity of coal and the moisture content. As the moisture content increases, the thermal conductivity increases. 
The calculation results show that when the water content is $3 \%, 8 \%, 30 \%, 50 \%$, the thermal conductivity of coal is $0.291,0.358,0.887,2.024 \mathrm{~W} \cdot(\mathrm{m} \cdot \mathrm{K})^{-1}$, respectively.

2) The simulation results using COMSOL numerical software show that the greater the thickness of magma, the higher the maximum temperature reached by the coal seam, the longer the duration, and the higher the final temperature retained. The closer the distance to the magma, the higher the temperature reached by the coal seam and the longer it will take. After the magma cools, the closer to the magma, the higher the final retention temperature of the coal seam, but the difference is small. Close to the magma, the $R_{o}$ of coal and the peak temperature of magma tend to increase. The results show that the thermal evolution of magma significantly improves the organic maturity of coal. The distance to the magma decreases from $50 \mathrm{~m}$ to $10 \mathrm{~m}$, the $\mathrm{R}_{\mathrm{o}}$ of coal increases from $1.25 \%$ to $11.32 \%$, and the peak magma temperature increases from $180.18{ }^{\circ} \mathrm{C}$ to $462.50{ }^{\circ} \mathrm{C}$.

3) With the increase of water content, the thermal conductivity of coal increases, and the heat flow rate increases. The heat transferred from the magma to the distance increases, so does the heat loss from magma. With the increase of water content, the cooling time of magma decreases, the maximum temperature of coal seam decreases significantly, and the time to reach the maximum temperature is also shorter. As the water content increases from $0 \%$ to $50 \%$, the maximum temperature of coal seam decreases from $120{ }^{\circ} \mathrm{C}$ to $35{ }^{\circ} \mathrm{C}$. The $\mathrm{R}_{\mathrm{o}}$ of coal decreases from $0.78 \%$ to $0.40 \%$. It shows that the existence of water significantly reduces the maximum temperature of coal seam, weakens the thermal evolution of magma on coal, and causes the metamorphic degree of coal to be lower than expected.

4) The moisture and $R_{o}$ measured by coal samples collected on the No.7 coal seam of Daxing Mine verified the numerical simulation results of magma thermal evolution to some extent. The baking or heat flow of magma reduces the vaporization and evaporation of water in coal. Therefore, the existence of low rank coal with high moisture reduces the thermal evolution of magma in Daxing Mine, resulting in the maturity of the No. 7 coal seam being lower than expected.

\section{Acknowledgements}

The authors are grateful to the Fundamental Research Funds for the National Natural Science Foundation of China (No. 51874298), the Priority Academic Program Development of 
Jiangsu Higher Education Institutions (PAPD) and the University Cyan Project of the Jiangsu Province.

\section{Declaration of interests}

The authors declare that they have no known competing financial interests or personal relationships that could have appeared to influence the work reported of this paper in Environmental Earth Sciences.

\section{References}

[1] Aarnes I, Svensen H, Polteau S, Planke S (2011) Contact metamorphic devolatilization of shales in the Karoo Basin, South Africa, and the effects of multiple sill intrusions. Chem. Geol 281: 181-194

[2] Barker CE, Pawlewicz MJ (1994) Calculation of vitrinite reflectance from thermal histories and peak temperatures: A comparison of methods. Vitrinite Reflectance as a Maturity Parameter: Amer. Chem. Soc. Symp (In: Mukhopadhyay, P.K., Dow, W.G.(Eds.) 570: 216-229.

[3] Beamish BB, Crosdale PJ (1998) Instantaneous outbursts in underground coal mines: An overview and association with coal type. Int J Coal Geol 35(1-4): 27-55.

[4] Carslaw HS, Jaeger JC (1959) Conduction of Heat in Solids. Oxford University Press, Oxford, UK, pp 273-281

[5] Charles EB, Yvonne B, Michael DL (1998) Fluid inclusion and vitrinite reflectance geothermometry compared to heat-flow models of maximum paleotemperature next to dikes, western onshore Gippsland Basin, Australia. Int J Coal Geol 37(1-2):73-111

[6] Delaney PT (1988) FORTRAN 77 programs for conductive cooling of dikes with temperature-dependent thermal properties and heat of crystallization. Computers \& Geosciences 14(2):181-212

[7] Dutcher RR, Campbell DA, Thornton, CP (1968) Coal metamorphism and igneous intrusions in Colorado. Coal Science 55: 708-723

[8] Feng JJ, Wang E, Huang QS, Ding HC, Zhang XY (2020) Experimental and numerical study of failure behavior and mechanism of coal under dynamic compressive loads. International Journal of Mining Science and Technology 30(5):613-21

[9] Finkelman RB, Bostick NH, Dulong FT, Senftle FE (1998) Influence of an igneous intrusion on the inorganic geochemistry of a bituminous coal from Pitkin County, Colorado. Int J 
Coal Geol 36: 223-241

[10] Fjeldskaar W, Helset HM, Johansen H, Grunnaleite I, Horstad I (2008) Thermal modelling of magmatic intrusions in the Gjallar Ridge, Norwegian Sea-implications for vitrinite reflectance and hydrocarbon maturation. Basin Research 20:143-159

[11] Galushkin YI (1997) Thermal effects of igneous intrusions on maturity of organic matter: A possible mechanism of intrusion. Organic Geochemistry 26(11-12):645-658

[12] Golab AN, Carr PF (2004) Changes in geochemistry and mineralogy of thermally altered coal, Upper Hunter Valley, Australia. Int J Coal Geol 57(3-4): 197-210

[13] Hu AJ, Lu CM, Wang YY, Yu MZ (2016) Liquid distribution and mechanism in heated wet porous medium (in Chinese). Journal of Engineering Thermophysics 37(7):1544-1549

[14] Jaeger JC (1957) The temperature in the neighborhood of a cooling intrusive sheet. American Journal of Science 255(4):306-318

[15] Jaeger JC (1959) Temperatures outside a cooling intrusive sheet. American Journal Ofence 257(1):44-54

[16] Jiang JY, Cheng YP, Wang L, Li W, Wang L (2011) Petrographic and geochemical effects of sill intrusions on coal and their implications for gas outbursts in the Wolonghu Mine, Huaibei Coalfield, China. International Journal of Coal Geology 88 (2011) 55-66

[17] Jiang J Y, Yang WH, Cheng YP, Liu ZD, Zhang Q, Zhao K (2019) Molecular structure characterization of middle-high rank coal via XRD, Raman and FTIR spectroscopy: Implications for coalification. Fuel 239:559-572

[18] Jiang JY, Zhang Q, Cheng YP, Jin K, Zhao W, Guo HJ (2016) Influence of thermal metamorphism on CBM reservoir characteristics of low-rank bituminous coal. Journal of Natural Gas Science and Engineering 36: 916-930

[19] Jiang JY, Zhang Q, Cheng YP, Wang HF, Liu ZD (2017) Quantitative investigation on the structural characteristics of thermally metamorphosed coal: evidence from multi-spectral analysis technology. Environ Earth Sci 76(11):406

[20] Ma L, We GM, Li ZB, Qin XY (2017) Experimental research on the influencing factors of thermal conductivity of coal (in Chinese). Mining safety \& environmental protection 44 (2):31-34

[21] Pan HL. (2000) Calculation of effective heat conductivities in highly porous media (in 
Chinese). Aviation Computing Technology 30(3):12-14

[22] Rahman MW, Rimmer SM (2014) Effects of rapid thermal alteration on coal: Geochemical and petrographic signatures in the Springfield (No. 5) Coal, Illinois Basin. Int J Coal Geol $131: 214-226$

[23] Sachsenhofer RF, Privalov VA, Panova EA (2012) Basin evolution and coal geology of the Donets Basin (Ukraine, Russia): An overview. Int J Coal Geol 89: 26-40

[24] Saikia BK, Saikia A, Choudhury R, Xie PP, Liu JJ, Das T, Dekaboruah HP (2016) Elemental geochemistry and mineralogy of coals and associated coal mine overburden from Makum coalfield (Northeast India). Environ Earth Sci 75(8):660

[25] Sasaki M (1959) On the coal affected by the thermal metamorphism through the intrusion of the igneous rock in the Tagawa district, Chikuho coal field, Kyushu (in Japanese with English abstract). Jpn. Geol. SurV. Bull 10: 103-110

[26] Shang Y (2012) The investigation on heat and mass transfer of moisture soil intermittent store and exothermic process (in Chinese). Dissertation, Dalian University of Technology

[27] Shivanna M, Murthy S, Singh VP, Roy JS (2015) Thermally Altered Coals from Bore Core EBM-1, East Bokaro Coal Field, Damodar Valley, India: A Petrographic Inference. Journal of the Geological Society of India 86(5):535-546

[28] Su CD, Qiu JD, Wu QH, Weng L (2020) Effects of high temperature on the microstructure and mechanical behavior of hard coal. International Journal of Mining Science and Technology 30(5):643-50

[29] Thussu S, Datta A (2011) Fundamentals-based quality prediction: Texture development during drying and related processes. Procedia Food Science 1(1):1209-1215

[30] Wang DY, Lu XC, Zhang XJ, Xu SJ, Hu WX, Wang LS (2007) Heat-model analysis of wall rocks below a diabase sill in Huimin Sag, China compared with thermal alteration of mudstone to carbargilite and hornfels and with increase of vitrinite reflectance. Geophysical Research Letters 34(16):130-144

[31] Wang DY, Lu XC, Song YC, Shao R, Qi T (2010a) Influence of the temperature dependence of thermal parameters of heat conduction models on the reconstruction of thermal history of igneous-intrusion-bearing basins. Computers \& Geosciences 36(10):1339-1344 
[32] Wang DY, Song YC, Liu WG, Zhao ML, Qi T (2011) Numerical investigation of the effect of volatilization and the supercritical state of pore water on maturation of organic matter in the vicinity of igneous intrusions. Int J Coal Geol 87:33-40

[33] Wang DY (2013a) MagmaHeatNS1D: One-dimensional visualization numerical simulator for computing thermal evolution in a contact metamorphic aureole. Computers \& Geosciences 54:21-27

[34] Wang DY, Song YC, Xu HS, Ma XJ, Zhao ML (2013b) Numerical modeling of thermal evolution in the contact aureole of a $0.9 \mathrm{~m}$ thick dolerite dike in the Jurassic siltstone section from Isle of Skye, Scotland. Journal of Applied Geophysics 89:134-140

[35] Wang K, Lu XC, Chen M, Ma YM, Liu KY, Liu LQ, Li XZ, Hu WX (2012) Numerical modelling of the hydrocarbon generation of Tertiary source rocks intruded by doleritic sills in the Zhanhua depression, Bohai Bay Basin, China. Basin Research 24:234-247

[36] Wang L, Cheng LB, Cheng YP, Yin GZ, Cai CC, Xu C, Jin K (2014) Thermal effects of magmatic sills on coal seam metamorphism and gas occurrence. Bull Volcanol 76: 803

[37] Wang M, Lu SF, Xue HT, Wu J, Liu DW (2010b) The effects of magmatic intrusions on the maturation of organic matter and its numerical simualtion. Acta Petrologica Sinica 26(1):177-184

[38] Xu TT, Zhan SL (2010) Theoretical calculation of effective thermal conductivity of wet porous building materials (in Chinese). Low Temperature Architecture Technology 32(6):119-120

[39] Yang Q, Wu CL, Tang DZ (1996) China coal metamorphism (in Chinese). Coal Industry Press. Xuzhou

[40] Yang SM, Tao WQ (2006) Heat Transfer (in Chinese). Higher Education Press. Beijing 


\section{Tables}

Table 1 Basic parameters in numerical simulation (Wang et al. 2011; Xu et al. 2010; Hu et al. 2016; Thussu and Datta 2011; Shang et al. 2012)

\begin{tabular}{|c|c|c|c|}
\hline Name & Symbol & Unit & Value \\
\hline Thermal conductivity of magma & $\lambda_{1}$ & $\mathrm{~W} \cdot(\mathrm{m} \cdot \mathrm{K})^{-1}$ & 2.1 \\
\hline Thermal conductivity of coal & $\lambda_{2}$ & $\mathrm{~W} \cdot(\mathrm{m} \cdot \mathrm{K})^{-1}$ & 0.286 \\
\hline $\begin{array}{l}\text { Thermal conductivity of } \\
\text { Surrounding rock }\end{array}$ & $\lambda_{3}$ & $\mathrm{~W} \cdot(\mathrm{m} \cdot \mathrm{K})^{-1}$ & 2.64 \\
\hline Magma density & $\rho_{1}$ & $\mathrm{~kg} / \mathrm{m}^{3}$ & 2700 \\
\hline Density of coal & $\rho_{2}$ & $\mathrm{~kg} / \mathrm{m}^{3}$ & 1314 \\
\hline Density of surrounding rock & $\rho_{3}$ & $\mathrm{~kg} / \mathrm{m}^{3}$ & 2510 \\
\hline Magma specific heat capacity & $C_{1}$ & $\mathrm{~J} \cdot(\mathrm{kg} \cdot \mathrm{K})^{-1}$ & 1213 \\
\hline Specific heat capacity of coal & $\mathrm{C}_{2}$ & $\mathrm{~J} \cdot(\mathrm{kg} \cdot \mathrm{K})^{-1}$ & 883 \\
\hline $\begin{array}{l}\text { Specific heat capacity of } \\
\text { Surrounding rock }\end{array}$ & $\mathrm{C}_{3}$ & $\mathrm{~J} \cdot(\mathrm{kg} \cdot \mathrm{K})^{-1}$ & 870 \\
\hline Thermal conductivity of water & $\lambda_{w}$ & $\mathrm{~W} \cdot(\mathrm{m} \cdot \mathrm{K})^{-1}$ & 0.6 \\
\hline Density of water & $\rho_{W}$ & $\mathrm{~kg} / \mathrm{m}^{3}$ & 1000 \\
\hline Specific heat of water & $C_{w}$ & $\mathrm{~J} \cdot(\mathrm{kg} \cdot \mathrm{K})^{-1}$ & 4180 \\
\hline Thermal conductivity of gas & $\lambda_{\mathrm{g}}$ & $\mathrm{W} \cdot(\mathrm{m} \cdot \mathrm{K})^{-1}$ & 0.026 \\
\hline $\begin{array}{c}\text { Latent heat of magma phase } \\
\text { Transition }\end{array}$ & $\mathrm{L}_{\mathrm{c}}$ & $\mathrm{kJ} / \mathrm{kg}$ & 376 \\
\hline Latent heat of water phase change & $\mathrm{L}_{\mathrm{v}}$ & $\mathrm{kJ} / \mathrm{kg}$ & 2410 \\
\hline Magma phase transition interval & $T_{\mathrm{c} 1}-T_{\mathrm{c} 2}$ & ${ }^{\circ} \mathrm{C}$ & $350-650$ \\
\hline Water phase change interval & $T_{11}-T_{12}$ & ${ }^{\circ} \mathrm{C}$ & 297-302 \\
\hline
\end{tabular}

Table 2 Physical parameters of phase change materials (Wang et al. 2017)

\begin{tabular}{cccc}
\hline Material & Phase transition state & Density & $\begin{array}{c}\text { Specific heat } \\
\text { capacity }\end{array}$ \\
\hline \multirow{2}{*}{ Magma } & Before phase change & 2.10 & 2700 \\
\cline { 2 - 4 } & After phase change & 2.64 & 2510 \\
\hline \multirow{2}{*}{ Coal } & Before phase change & 800 & 883 \\
\cline { 2 - 4 } & After phase change & 1290 & 1076 \\
\hline
\end{tabular}

Table 3 Thermal conductivity of coal under different moisture content

\begin{tabular}{ccccc}
\hline Moisture $\omega$ & $50 \%$ & $30 \%$ & $8 \%$ & $3 \%$ \\
\hline Effective thermal conductivity $\lambda_{\mathrm{e}} / \mathrm{W} \cdot(\mathrm{m} \cdot \mathrm{K})^{-1}$ & 2.024 & 0.887 & 0.358 & 0.291 \\
\hline
\end{tabular}




\section{Figure captions}

Fig. 1 Thermal conductivity of coal varies with moisture, modified from

Fig. 2 Numerical simulation model 1

Fig. 3 Thermal evolution of coal seam with different magma thickness

Fig. 4 Numerical simulation model 2

Fig. 5 Temperature of coal varies with time at different distances from magma

Fig. 6 Numerical simulation model 3

Fig. 7 Temperature of coal with different moisture content after magma intrusion

Fig. 8 Numerical simulation model 4

Fig. 9 Coal temperature changes with time under different moisture content

Fig. 10 Location of $\mathrm{N}_{1} 708$ coalface and distribution plan of sill in Daxing Mine

Fig. 11 Relationships between moisture, $R_{o}$ and the distance from igneous sill in Daxing Mine (a), relationship between coal peak temperature and the distance from sill (b)

\section{Table captions}

Table 1 Basic parameters in numerical simulation

Table 2 Physical parameters of phase change materials

Table 3 Thermal conductivity of coal under different moisture content 
Figures

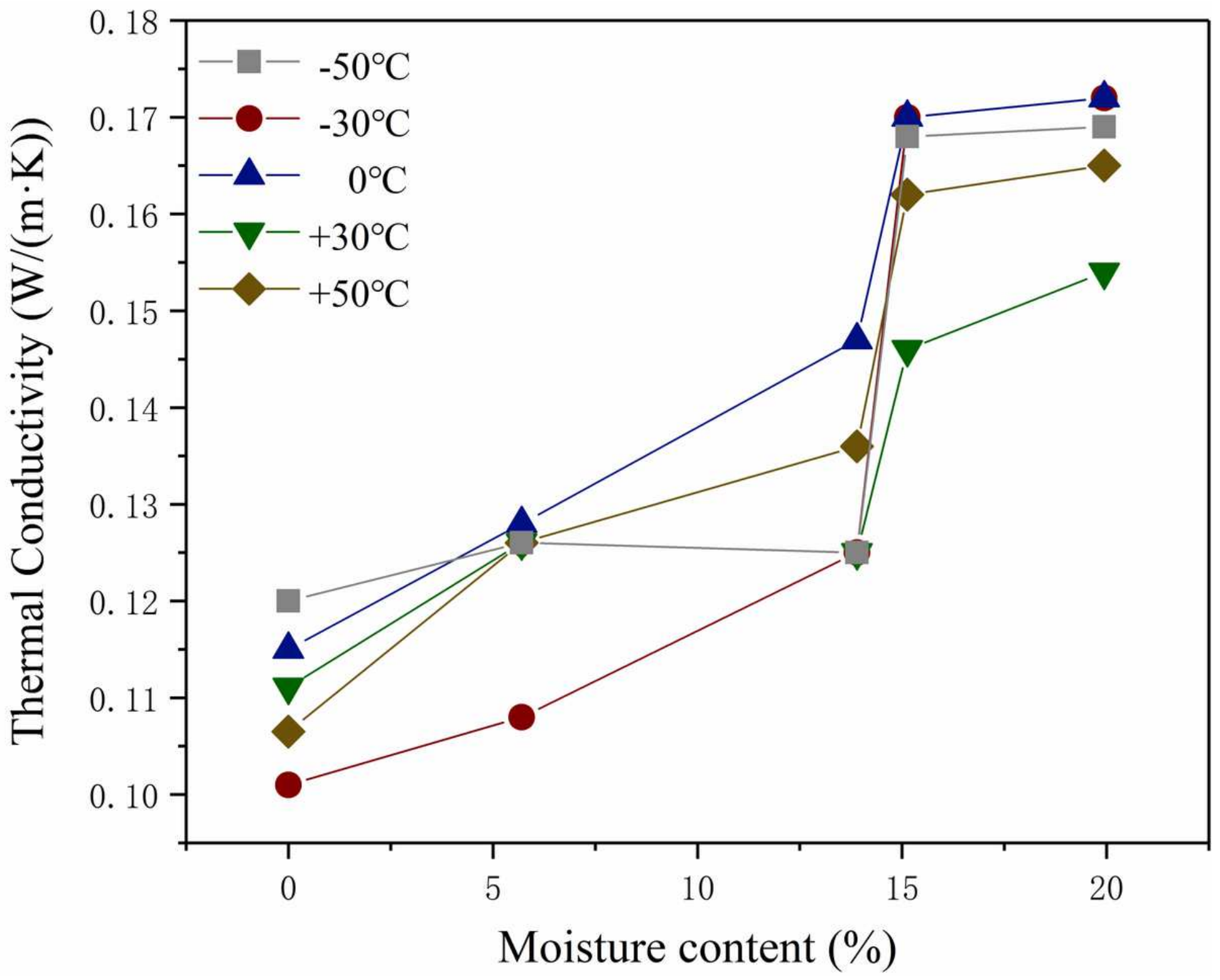

Figure 1

Thermal conductivity of coal varies with moisture, modified from 


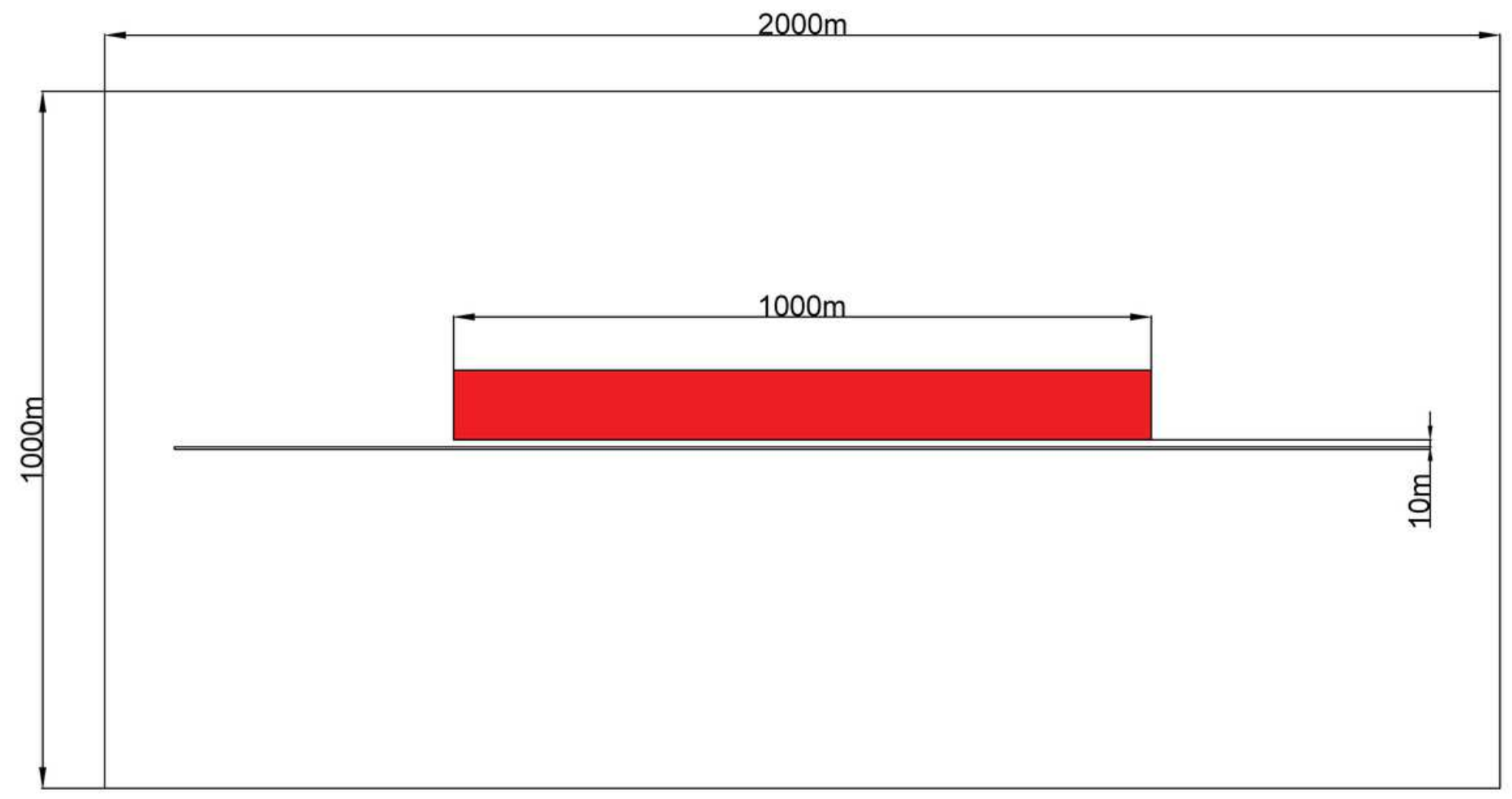

Figure 2

Numerical simulation model 1 


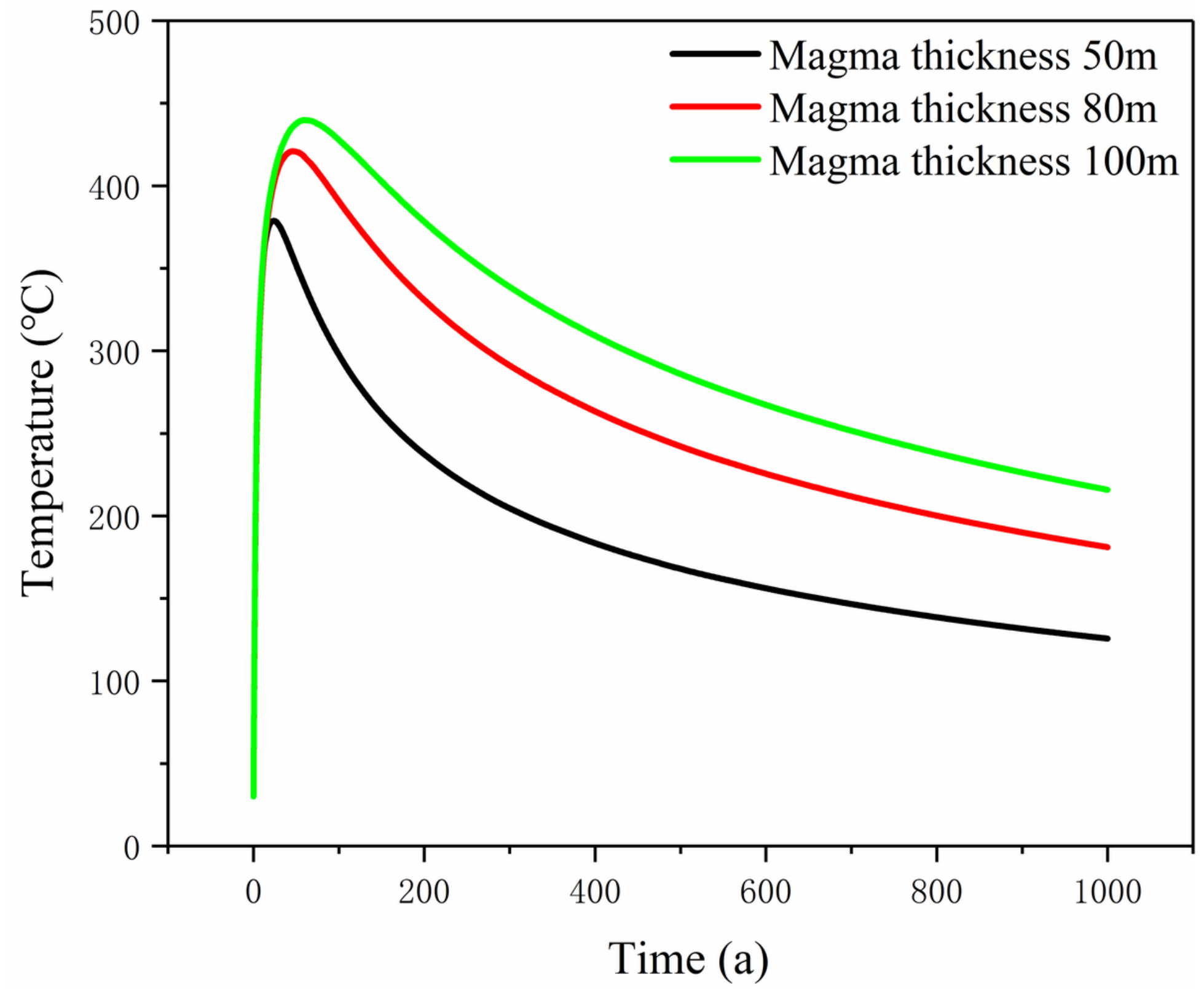

Figure 3

Thermal evolution of coal seam with different magma thickness 


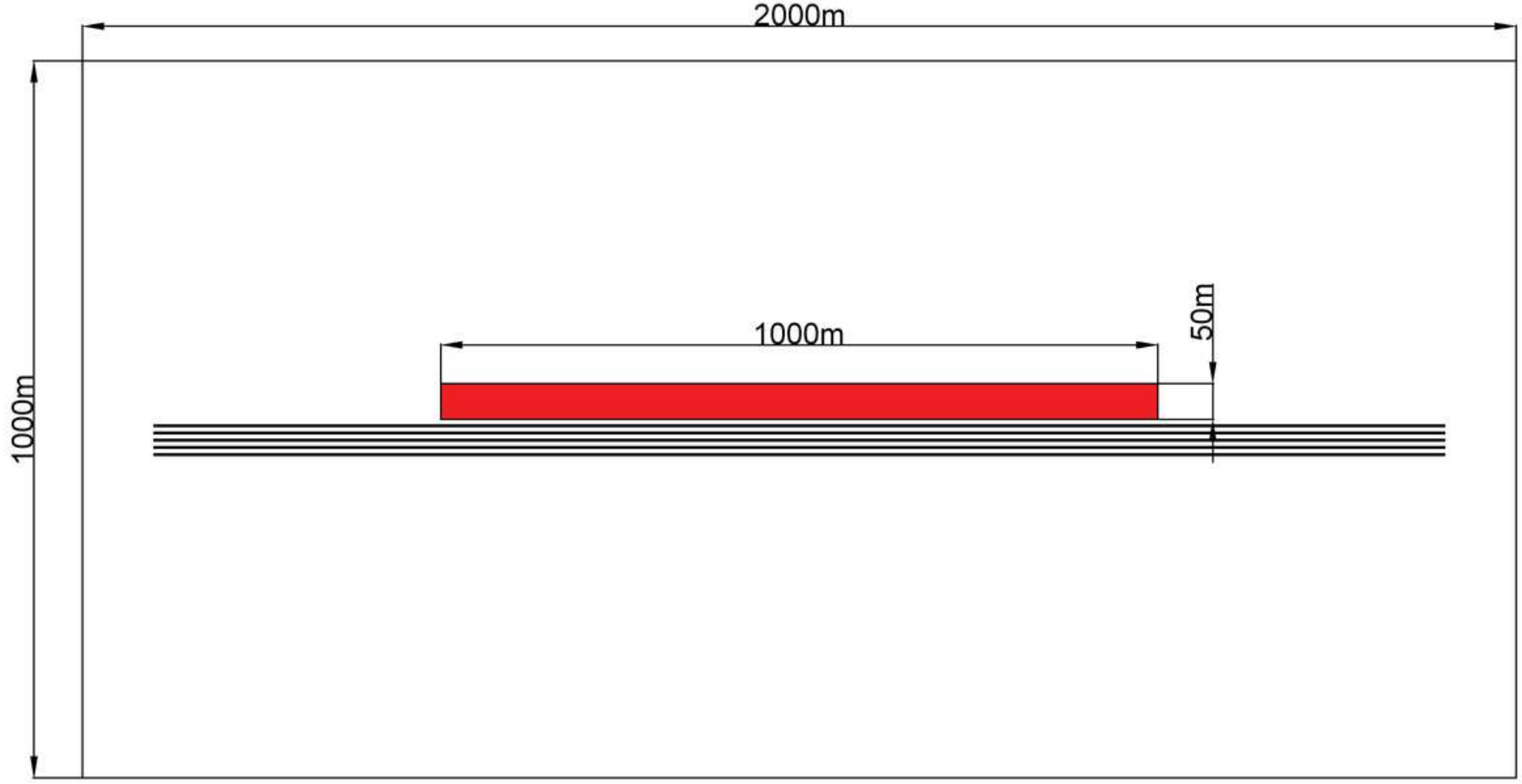

Figure 4

Numerical simulation model 2
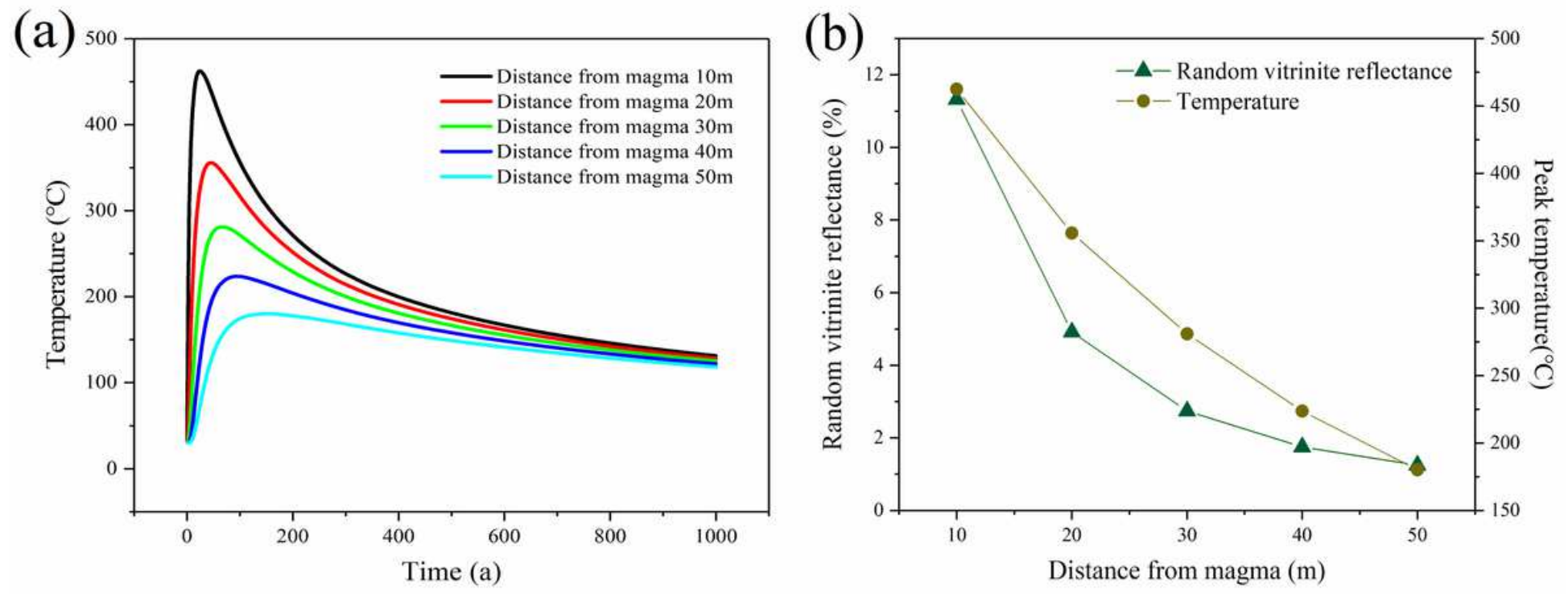

Figure 5

Temperature of coal varies with time at different distances from magma 


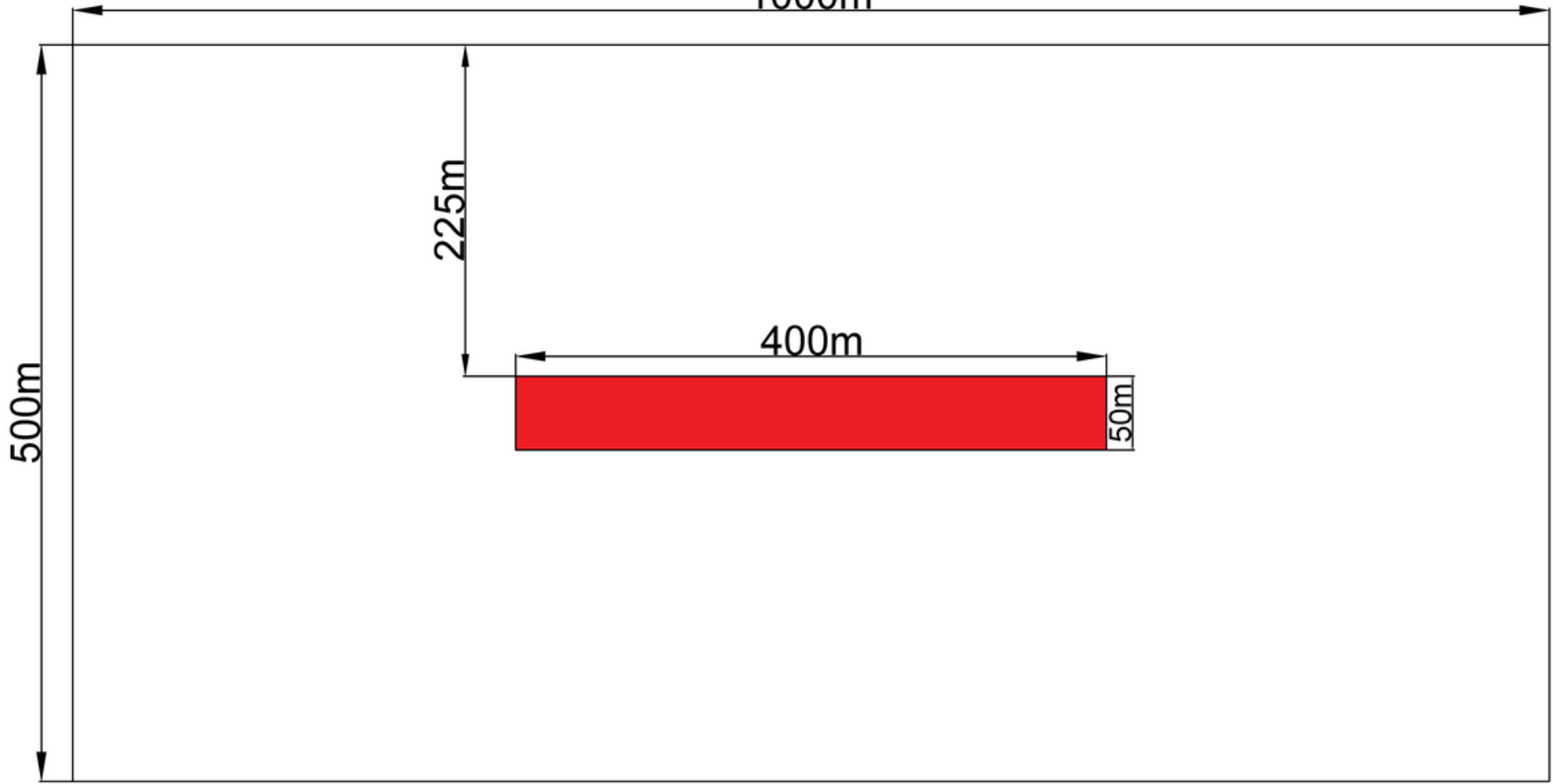

Figure 6

Numerical simulation model 3
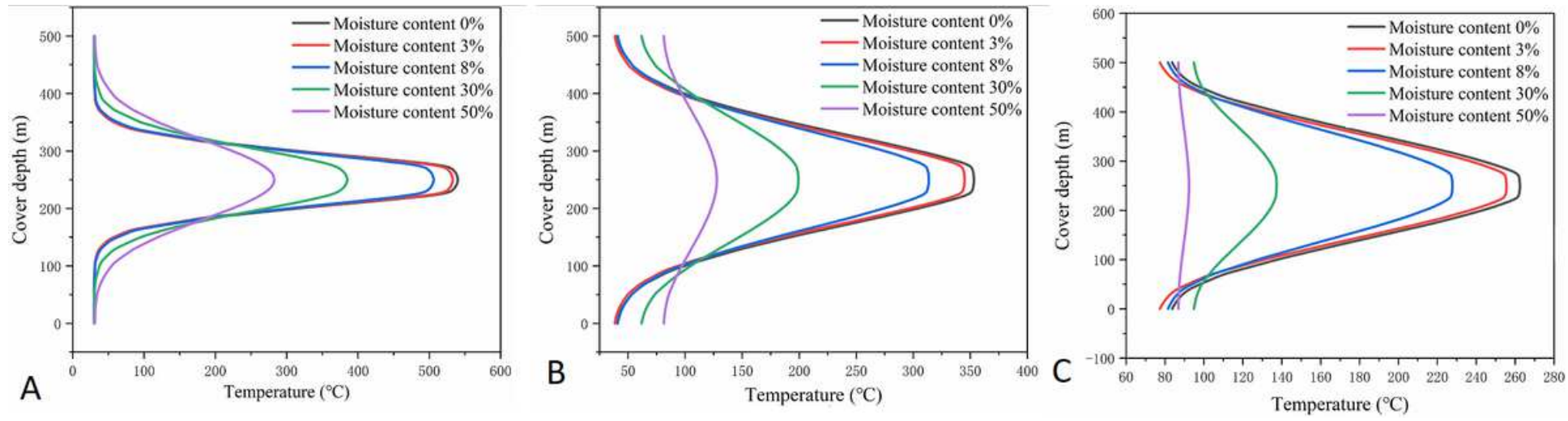

Figure 7

Temperature of coal with different moisture content after magma intrusion 


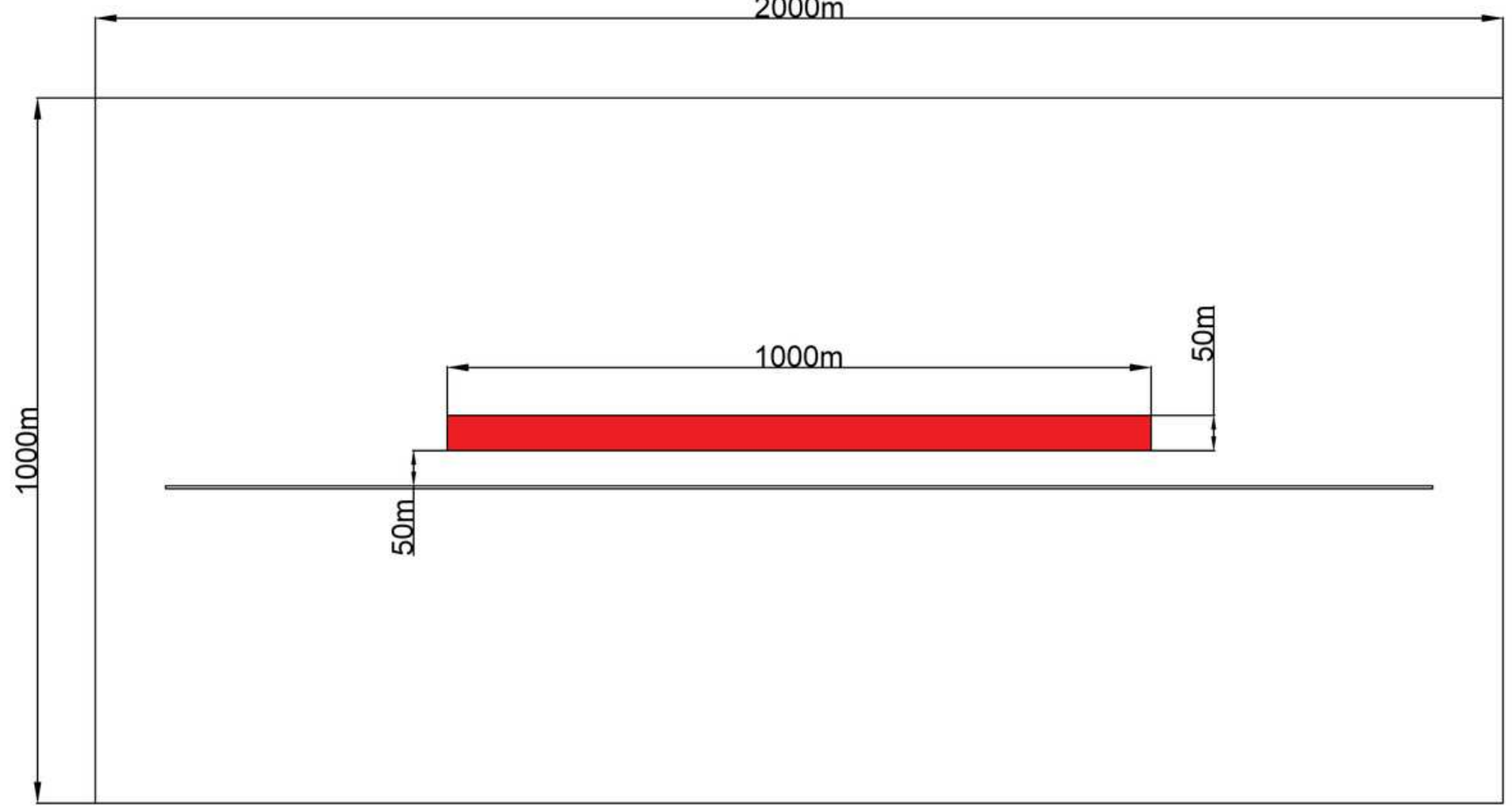

Figure 8

Numerical simulation model 4

(a)

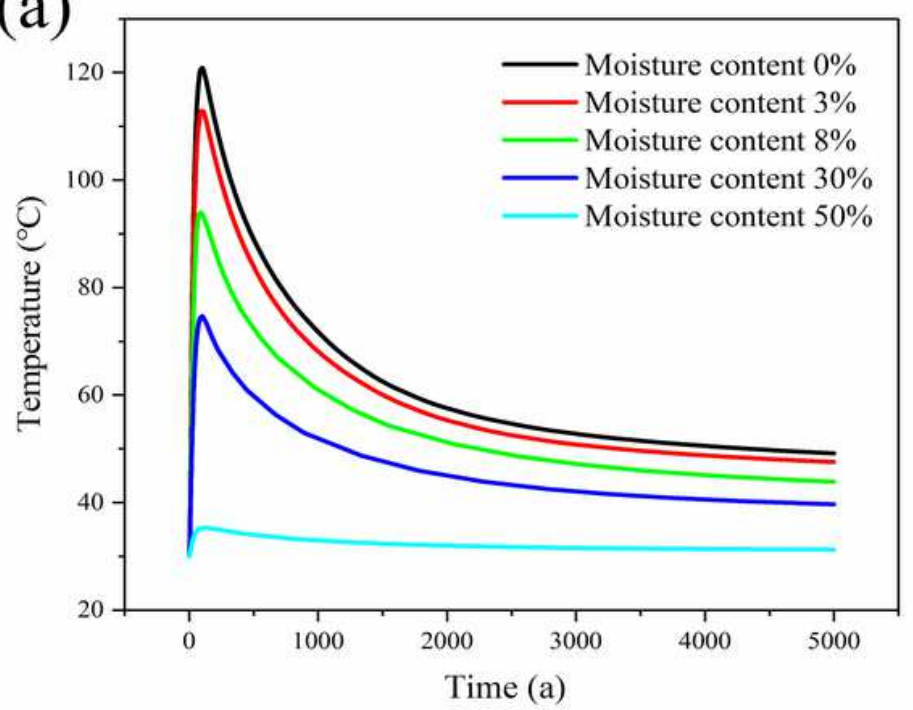

(b)

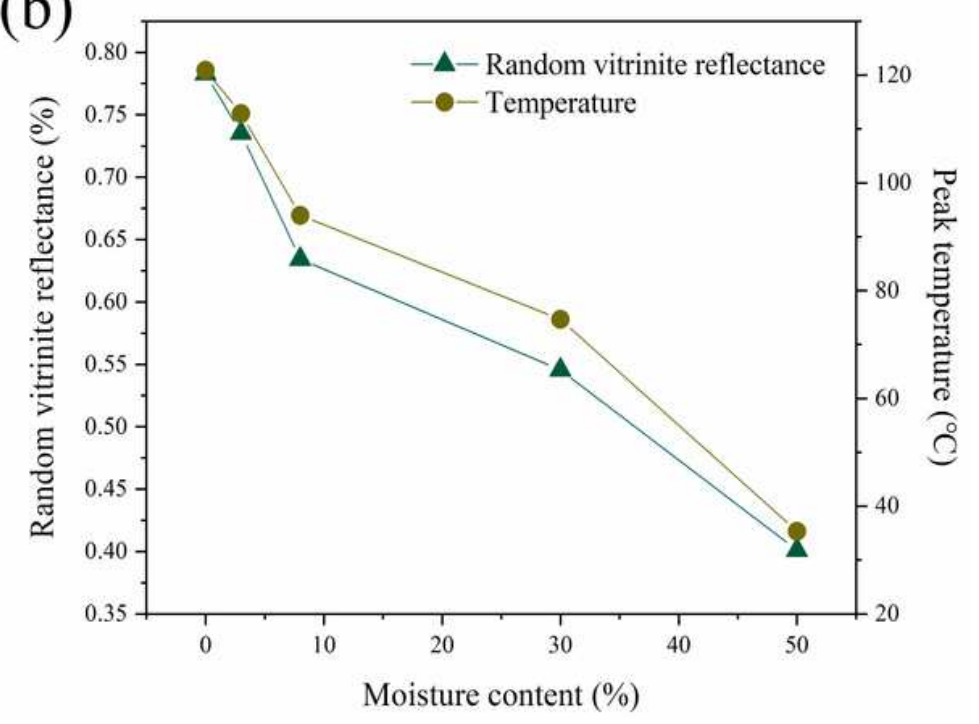

\section{Figure 9}

Coal temperature changes with time under different moisture content 


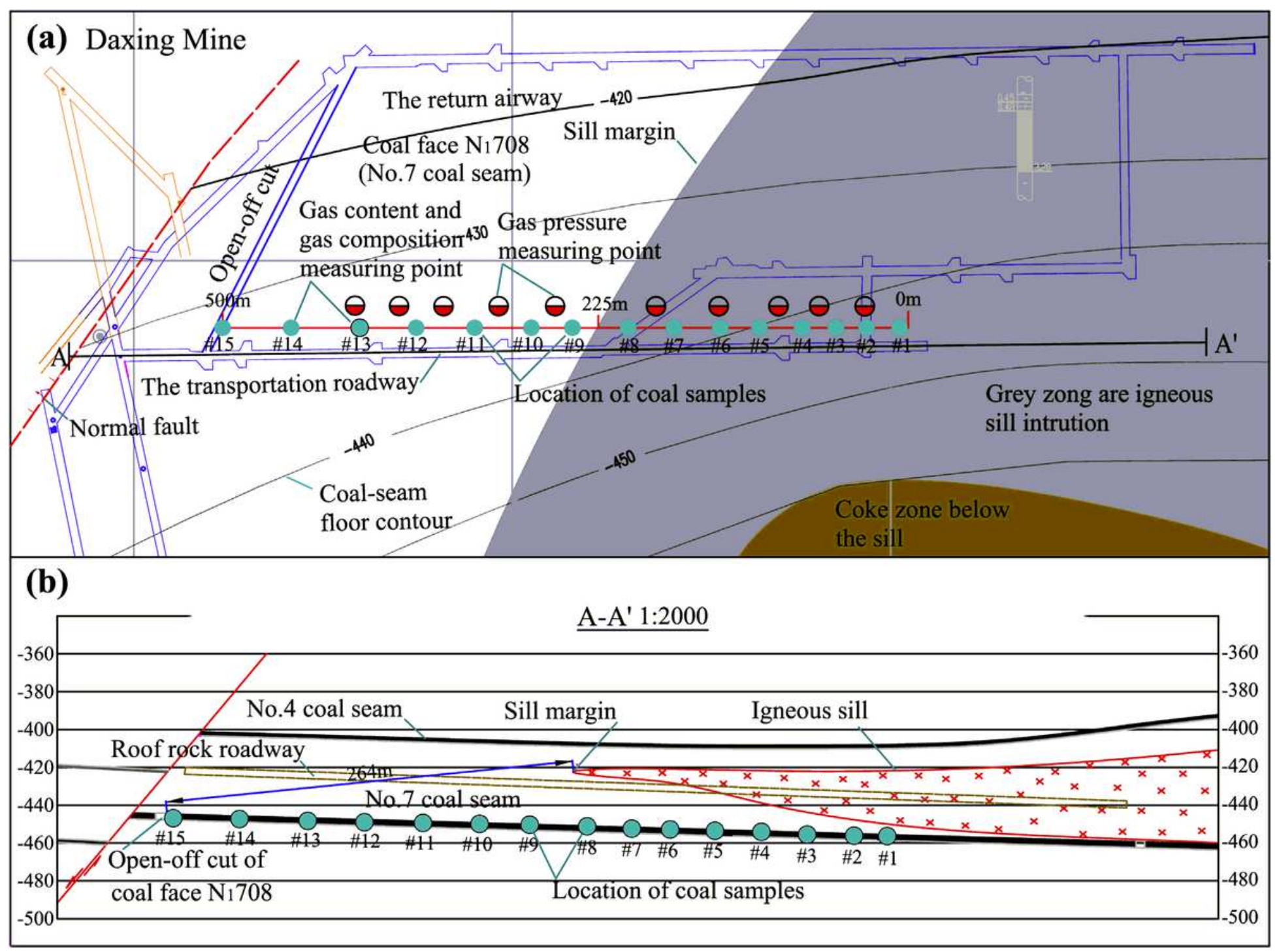

Figure 10

Location of N1708 coalface and distribution plan of sill in Daxing Mine

(a)

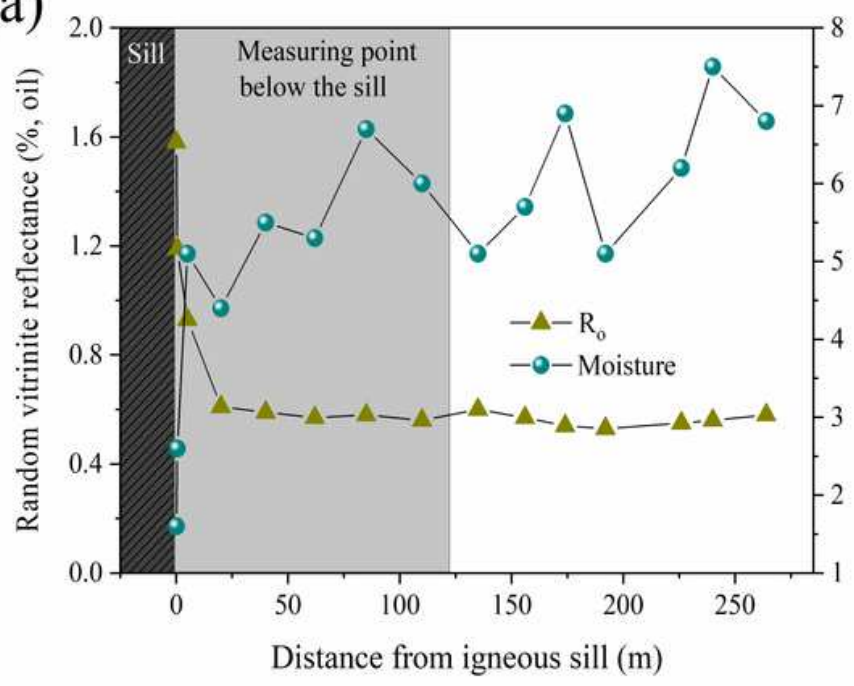

(b)

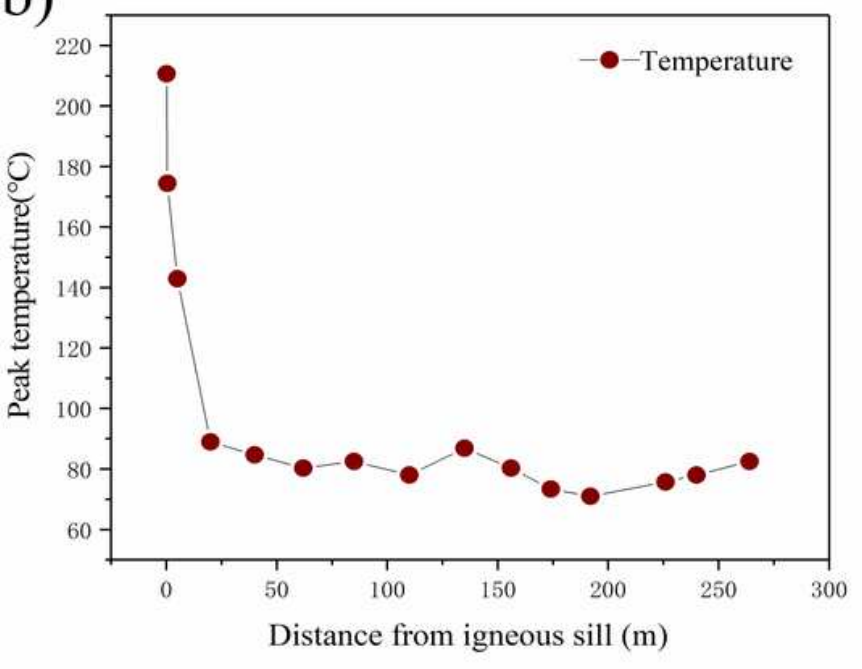




\section{Figure 11}

Relationships between moisture, Ro and the distance from igneous sill in Daxing Mine (a), relationship between coal peak temperature and the distance from sill (b) 